\title{
Massa alimentícia sem glúten com elevado teor proteico obtida por processo convencional
}

\author{
Gluten-free pasta with high protein content obtained by conventional processing
}

\author{
Marcio Schmiele $^{\mathrm{I}^{*}}$ Leandra Zafalon Jaekel $^{\mathrm{I}}$ Patricia Mello Garrido Ishida ${ }^{\mathrm{I}}$ Yoon Kil Chang ${ }^{\mathrm{I}}$ \\ Caroline Joy Steel ${ }^{\mathrm{I}}$
}

RESUMO

\begin{abstract}
Indivíduos celíacos necessitam de dieta sem glúten como, por exemplo, massas alimentícias de arroz. No entanto, esse cereal apresenta o menor teor de proteínas, em relação aos demais cereais, e deficiência em características tecnológicas de cozimento e textura para as massas alimentícias. $O$ objetivo deste trabalho foi desenvolver massa de farinha de arroz com alto teor de proteína através de Delineamento Composto Central Rotacional de três variáveis independentes, sendo: $X_{1}$ - isolado proteico de soja (IPS - 0-20\%); $X_{2}$ - albumina de ovo modificada e desidratada (ALB - 0-15\%); e $X_{3}$ - farinha de arroz prégelatinizada (FAG - 0-30\%). As massas foram analisadas quanto a tempo de cozimento (TC), perda de sólidos na água de cozimento $(P S)$, aumento de peso (AP), firmeza e adesividade. Verificou-se que a adição de IPS, ALB e FAG influenciou significativamente $(P<0,10)$ no TC, PS e firmeza, com valores entre 300 e $525 s$, 2,22 e 9,84\% e 4,82 e 11,13N, respectivamente. O ponto ótimo foi obtido com adição de $17 \%$ de IPS, $15 \%$ de ALB e $15 \%$ de $F A G$, indicando um produto com excelentes características de cozimento e textura para inclusão na dieta de celíacos.
\end{abstract}

Palavras-chave: doença celíaca, farinha de arroz, proteína de soja, albumina, massa sem glúten.

\section{ABSTRACT}

Celiac individuals require a gluten free diet, which includes products such as rice pasta. However, this cereal has lower protein content, when compared with other cereals, and poor cooking and texture technological characteristics for pasta. The aim of this research was the development of rice pasta with high protein content through a Central and Rotational Composite Design with three independent variables, as follows: $X_{1}$ - isolated soy protein (ISP - 0-20\%); $X_{2}$ - modified and dehydrated egg albumin ( $A L B-0-15 \%)$; and $X_{3}$ - pre-gelatinized rice flour (GRF $-0-30 \%)$. The pasta samples were analyzed for cooking time (CT), solid loss in cooking water (SL), weight gain $(W G)$, firmness and adhesiveness. It was verified that ISP, ALB and GRF significantly influenced $(P<0.10) C T, S L$ and firmness, with values between 300 and $525 \mathrm{~s}, 2.22$ and $9.84 \%$ and 4.82 and $11.13 N$, respectively. The optimum point was obtained with the addition of 17\% ISP, $15 \%$ $A L B$ and $15 \%$ GRF, indicating a product with excellent cooking and texture properties to include in the diet of celiacs.

Key words: celiac disease, rice flour, soy protein, albumin, gluten free pasta.

\section{INTRODUÇÃO}

Muitas pessoas apresentam reações alérgicas a determinados componentes dos alimentos, comprometendo sua saúde e reduzindo o número de opções na escolha da dieta. A doença celíaca é caracterizada por inflamação das células intestinais na presença do glúten, sendo que indivíduos que apresentam esta doença necessitam de uma dieta especial, ou seja, sem a presença do glúten (CATASSI \& FASANO, 2010).

$\mathrm{O}$ arroz é isento de glúten e constitui importante fonte de calorias na alimentação de mais da metade da população mundial. $\mathrm{O}$ beneficiamento do arroz resulta em aproximadamente $14 \%$ de grãos quebrados (quirera), os quais apresentam menor valor comercial ao serem moídos com a farinha (NABESHIMA \& EL DASH, 2004), e poderiam ser utilizados no desenvolvimento de produtos a base de arroz, tornando-os mais econômicos. No entanto, o arroz é o cereal com menor teor de proteínas (aproximadamente 7\%), sendo que estas apresentam baixo valor biológico.

IDepartamento de Tecnologia de Alimentos, Faculdade de Engenharia de Alimentos (FEA), Universidade Estadual de Campinas (UNICAMP), Rua Monteiro Lobato, 80, 13083-862, Campinas, SP, Brasil. E-mail: marcio.ufpel@ gmail.com. *Autor para correspondência. 
A combinação de arroz com soja é desejável em função do adequado balanço de aminoácidos essenciais. $\mathrm{O}$ arroz é rico em ácido glutâmico e aspártico, mas apresenta a lisina como aminoácido limitante, sendo este abundante na soja, a qual promove efeitos benéficos à saúde (FERNANDES et al., 2000), pois $25 \mathrm{~g}$ de ingestão diária da proteína de soja é recomendada (FDA, 1999), permitindo apelo de alimento funcional. Dentre os principais produtos derivados da soja, está o isolado proteico, que constitui uma forma comercial altamente purificada de proteína de soja.

Além de favorecer o valor nutricional, a proteína da soja pode melhorar as características tecnológicas de massas alimentícias, como suas propriedades de cozimento e de textura. Outras fontes proteicas que podem ser utilizadas e apresentam excelentes propriedades nutricionais e tecnológicas são as proteínas da clara do ovo que, em massas alimentícias, têm função como agente ligante. As propriedades funcionais tecnológicas dessas proteínas estão relacionadas à geleificação proteica, que consiste na formação de uma rede ordenada, capaz de manter a estrutura do produto final (PLANCKEN et al., 2005).

As características das massas alimentícias também podem ser favorecidas pelo uso de farinha de arroz pré-gelatinizado, devido ao aumento da tendência à retrogradação, propiciando assim maior rigidez aos grânulos de amido, implicando uma maior consistência após o cozimento e menor desintegração (NABESHIMA \& EL DASH, 2004). Segundo HUMMEL (1966), massa de trigo de boa qualidade deve apresentar perda de sólidos solúveis de no máximo $6 \%$ e aumento de peso de duas vezes e de volume de 2-3 vezes, ambos em relação ao volume inicial.

O objetivo deste trabalho foi desenvolver massa alimentícia sem glúten pelo processo convencional, utilizando farinha de arroz (FA), farinha de arroz pré-gelatinizada (FAG), isolado proteico de soja (IPS) e albumina de ovo modificada e desidratada (ALB).

\section{MATERIAL E MÉTODOS}

Matérias-primas

Foram utilizados farinha de arroz (FA) e farinha de arroz pré-gelatinizada (FAG) (Josapar, Pelotas, BRA), isolado proteico de soja (IPS) (Solae do Brasil Ind. e Com. de Alimentos, Esteio, BRA) e albumina de ovo modificada e desidratada (ALB) (AB Brasil Indústria e Comércio de Alimentos Ltda, Jundiaí, BRA).
Composição centesimal das matérias-primas

FA, FAG, IPS e ALB foram caracterizados através das seguintes análises: umidade, proteína bruta, cinzas e extrato etéreo, conforme os métodos 44-15.02, 46-13.01, 08-01.01 e 30-25.01 da AACC (2010), respectivamente. Carboidratos foram calculados por diferença.

\section{Delineamento experimental}

A elaboração das massas alimentícias foi realizada seguindo um Delineamento Composto Central Rotacional de três variáveis independentes sendo: $X_{1}$ - IPS $(0 ; 4 ; 10 ; 16$ e $20 \%) ; X_{2}-\operatorname{ALB}(0$; $3 ; 7,5 ; 12$ e $15 \%)$; e $X_{3}$ - FAG $(0 ; 6,1 ; 15 ; 23,9$ e $30 \%)$. O percentual de cada uma das variáveis foi em relação à FA. Também foi processado um ensaio controle, usando apenas FA (100\%).

Índice de absorção de água das pré-misturas

Para determinar a quantidade de água a ser adicionada em cada ensaio, determinou-se o índice de absorção de água (IAA) das pré-misturas (combinação de FA, IPS, ALB e FAG) de todos os ensaios do delineamento, conforme método proposto por ANDERSON et al. (1969). As amostras foram homogeneizadas por $4 \mathrm{~min}$ em batedeira planetária Kitchen Aid Professional, Model K45SS (St. Joseph, EUA), na velocidade 2.

\section{Produção das massas alimentícias}

A quantidade de água necessária para a elaboração das massas foi definida em $46 \%$ para o ponto central através de pré-testes. Para os demais ensaios, a quantidade de água foi calculada considerando-se o IAA. A água foi adicionada de forma contínua sob agitação em batedeira planetária por 2min, e as pré-misturas hidratadas foram colocadas em extrusor de massas Visa Máquinas para Macarrão, modelo Pastaia 2 (Tatuí, BRA), misturadas por 6min, seguidas de descanso de 4min e extrusão, no formato tipo espaguete, utilizando uma matriz com 32 aberturas de $1,7 \mathrm{~mm}$ de diâmetro. As massas de $50 \mathrm{~cm}$ de comprimento foram penduradas em varais e secas em estufa com circulação e renovação de ar da marca Tecnal, modelo TE-394/2 (Piracicaba, BRA), a $50 \pm 0,5^{\circ} \mathrm{C}$ por $2 \mathrm{~h}$ e $60 \pm 0,5^{\circ} \mathrm{C}$ por mais $2 \mathrm{~h}$.

Umidade e características de cozimento das massas alimentícias

A umidade foi determinada pelo método 44-15.02 da AACC (2010) e o tempo de cozimento (TC), a perda de sólidos na água de cozimento (PS) e o aumento de peso (AP) da amostra cozida dos

Ciência Rural, v.43, n.5, mai, 2013. 
ensaios e da amostra padrão foram determinados segundo o método 66-50.01 da AACC (2010).

Propriedades de textura

A textura das massas cozidas (no tempo estabelecido na análise de TC) foi avaliada em Texturômetro TA-XT2i Stable Micro Systems (Haslemere - GBR) com plataforma HDP/90, analisando-se a firmeza e a adesividade, com os probes, $\mathrm{A} / \mathrm{LKB}$ e HDP/PFS, respectivamente, conforme método 66-50.01 da AACC (2010). Os parâmetros para firmeza foram: velocidade pré-teste $2,0 \mathrm{~mm} \mathrm{~s}^{-1}$, teste $0,17 \mathrm{~mm} \mathrm{~s}^{-1}$ e pós-teste $10,0 \mathrm{~mm} \mathrm{~s}^{-1}$; distância $4,7 \mathrm{~mm}$; e para adesividade: velocidade préteste $1,0 \mathrm{~mm} \mathrm{~s}^{-1}$, teste $0,5 \mathrm{~mm} \mathrm{~s}^{-1}$ e pós-teste $10,0 \mathrm{~mm}$ $\mathrm{s}^{-1}$; distância $10,0 \mathrm{~mm}$, força de $1000 \mathrm{~g}$ e tempo de $2 \mathrm{~s}$.

Análise estatística

A análise estatística foi realizada utilizando-se o software Statistica 7.0 - Statsoft, (Tulsa, EUA). Os resultados obtidos para as matériasprimas foram avaliados por comparação de médias feita pelo teste de Tukey $(\alpha<0,05)$ e os dados obtidos nos ensaios do delineamento foram avaliados através da Metodologia de Superfície de Resposta para cálculo do coeficiente de regressão e análise de variância (ANOVA) $(\alpha<0,10)$, com coeficiente de determinação mínimo $\left(\mathrm{R}^{2}\right)$ da ANOVA de 0,75 . Os modelos matemáticos estão apresentados pelos níveis codificados para as variáveis independentes $\mathrm{x}_{1}, \mathrm{x}_{2} \mathrm{e}$ $\mathrm{x}_{3}$, respectivos ao IPS, ALB e FAG.

Validação dos modelos matemáticos

Depois de avaliados os modelos matemáticos e analisadas as superfícies de resposta, o ponto ótimo foi processado, em triplicata, conforme os ensaios do delineamento, e avaliado em relação ao IAA da pré-mistura e TC, PS e firmeza das massas.

\section{RESULTADOS E DISCUSSÃO}

Composição centesimal das matérias-primas

A composição centesimal das matériasprimas encontra-se na tabela 1. IPS e ALB apresentaram os maiores valores de proteínas e cinzas, sendo estatisticamente $(\mathrm{P}<0,05)$ maior para o IPS. O teor proteico do IPS está de acordo com os valores estabelecidos pela Agência Nacional de Vigilância Sanitária (ANVISA), através da RDC 268/2005 (BRASIL, 2005) que especifica um teor mínimo de $88 \%$. A ALB apresentou a maior concentração de cinzas $(\mathrm{P}<0,05)$. Em contrapartida, FA e FAG apresentaram maiores teores de carboidratos por serem ricas em amido. Valor semelhante para farinha de arroz foi encontrado na tabela brasileira de composição de alimentos (TACO, 2011).

Índice de absorção de água das pré-misturas

Os resultados de IAA das pré-misturas variaram entre 2,78 e 3,72 (Tabela 2) e foram influenciados $(\mathrm{P}<0,10)$ pela adição do IPS e da FAG. A ANOVA mostrou valor de $\mathrm{R}^{2}$ de $0,9831, \mathrm{~F}_{\text {calc }} / \mathrm{F}_{\text {tab }}$ de 21,61 e p-valor $<0,001$ e o modelo matemático gerado está na equação 1 . A figura 1 mostra que maiores valores de IAA foram obtidos nas maiores concentrações do IPS e da FAG, dentro da faixa estudada. A adição de ALB não afetou a absorção de água dos ensaios. A proteína de soja tem alto poder de hidratação, devido aos grupamentos hidrofílicos das cadeias de aminoácidos (EGBERT, 2004). A FAG favorece a absorção de água, devido à perda da cristalinidade das cadeias de amilopectina que ocorre durante a gelatinização do amido, expondo as hidroxilas (CLERICI \& EL-DASH, 2008). As proteínas que compõem a ALB são classificadas em proteínas solúveis em água (PLANCKEN et al.,

Tabela 1 - Composição centesimal das matérias-primas.

\begin{tabular}{|c|c|c|c|c|}
\hline Amostra & Farinha de arroz & $\begin{array}{c}\text { Farinha de arroz pré- } \\
\text { gelatinizada }\end{array}$ & Isolado proteico de soja & $\begin{array}{c}\text { Albumina modificada e } \\
\text { desidratada }\end{array}$ \\
\hline Umidade $(\%)$ & $6,53 \pm 0,02^{\mathrm{b}}$ & $5,29 \pm 0,13^{\mathrm{c}}$ & $6,75 \pm 0,13^{\mathrm{b}}$ & $7,46 \pm 0,08^{\mathrm{a}}$ \\
\hline Proteína $(\%)$ & $8,71 \pm 0,16^{\mathrm{c}}$ & $8,44 \pm 0,23^{d}$ & $88,38 \pm 0,28^{\mathrm{a}}$ & $85,96 \pm 0,21^{\mathrm{b}}$ \\
\hline Gordura (\%) & $0,38 \pm 0,04^{\mathrm{b}}$ & $0,70 \pm 0,12^{\mathrm{a}}$ & $0,37 \pm 0,20^{\mathrm{b}}$ & $0,12 \pm 0,02^{\mathrm{c}}$ \\
\hline Cinzas $(\%)$ & $0,39 \pm 0,03^{\mathrm{d}}$ & $0,45 \pm 0,01^{\mathrm{c}}$ & $4,31 \pm 0,01^{\mathrm{b}}$ & $4,78 \pm 0,03^{\mathrm{a}}$ \\
\hline Carboidratos $(\%)^{*}$ & 83,99 & 85,12 & 0,18 & 1,67 \\
\hline
\end{tabular}

Resultados da composição centesimal expressos em base úmida; média de três repetições \pm desvio padrão; *carboidratos calculados por diferença; médias com letras distintas na mesma linha apresentam diferença estatisticamente significativa entre as amostras através do teste de Tukey $(\mathrm{P}<0,05)$. 
Tabela 2 - Índice de absorção de água das pré-misturas e características de cozimento e textura das massas.

\begin{tabular}{|c|c|c|c|c|c|c|c|c|c|}
\hline \multirow{3}{*}{ Ensaio } & \multicolumn{3}{|c|}{------Níveis reais-----. } & \multirow{3}{*}{$\begin{array}{c}\text { Índice de absorção } \\
\text { de água* }\end{array}$} & \multirow{3}{*}{$\begin{array}{c}\text { Tempo de } \\
\text { cozimento (s)* }\end{array}$} & \multirow{3}{*}{$\begin{array}{c}\text { Perda de } \\
\text { sólidos }(\%)^{*}\end{array}$} & \multirow{3}{*}{$\begin{array}{l}\text { Aumento de } \\
\text { peso* }\end{array}$} & \multirow{3}{*}{$\begin{array}{l}\text { Firmeza } \\
(\mathrm{N})^{* *}\end{array}$} & \multirow{3}{*}{$\begin{array}{c}\text { Adesividade } \\
(\mathrm{N})^{* *}\end{array}$} \\
\hline & & & & & & & & & \\
\hline & $\mathrm{X}_{1}$ & $\mathrm{X}_{2}$ & $\mathrm{X}_{3}$ & & & & & & \\
\hline 1 & 4 & 3 & 6,1 & $2,78 \pm 0,05$ & $525 \pm 10$ & $7,95 \pm 0,35$ & $1,46 \pm 0,04$ & $6,79 \pm 0,47$ & $0,78 \pm 0,11$ \\
\hline 2 & 16 & 3 & 6,1 & $3,56 \pm 0,17$ & $345 \pm 15$ & $4,43 \pm 0,48$ & $1,27 \pm 0,03$ & $6,16 \pm 0,44$ & $1,03 \pm 0,13$ \\
\hline 3 & 4 & 12 & 6,1 & $2,86 \pm 0,10$ & $400 \pm 05$ & $2,56 \pm 0,07$ & $1,64 \pm 0,05$ & $11,13 \pm 0,92$ & $0,13 \pm 0,02$ \\
\hline 4 & 16 & 12 & 6,1 & $3,32 \pm 0,17$ & $340 \pm 07$ & $2,41 \pm 0,01$ & $1,50 \pm 0,11$ & $11,10 \pm 1,00$ & $0,49 \pm 0,01$ \\
\hline 5 & 4 & 3 & 23,9 & $3,06 \pm 0,12$ & $480 \pm 12$ & $9,84 \pm 0,31$ & $1,68 \pm 0,02$ & $5,35 \pm 0,42$ & $0,86 \pm 0,07$ \\
\hline 6 & 16 & 3 & 23,9 & $3,59 \pm 0,01$ & $350 \pm 14$ & $5,57 \pm 0,58$ & $1,36 \pm 0,04$ & $4,82 \pm 0,37$ & $1,01 \pm 0,13$ \\
\hline 7 & 4 & 12 & 23,9 & $3,04 \pm 0,10$ & $540 \pm 19$ & $3,20 \pm 0,02$ & $1,63 \pm 0,05$ & $8,75 \pm 0,48$ & $0,84 \pm 0,13$ \\
\hline 8 & 16 & 12 & 23,9 & $3,72 \pm 0,09$ & $410 \pm 11$ & $2,60 \pm 0,06$ & $1,65 \pm 0,03$ & $7,50 \pm 0,51$ & $0,51 \pm 0,01$ \\
\hline 9 & 0 & 7,5 & 23,9 & $2,78 \pm 0,01$ & $510 \pm 17$ & $6,34 \pm 0,43$ & $1,55 \pm 0,04$ & $7,98 \pm 0,49$ & $0,88 \pm 0,11$ \\
\hline 10 & 20 & 7,5 & 23,9 & $3,60 \pm 0,16$ & $325 \pm 04$ & $2,66 \pm 0,07$ & $1,46 \pm 0,05$ & $9,90 \pm 0,79$ & $0,29 \pm 0,05$ \\
\hline 11 & 10 & 0 & 23,9 & $3,39 \pm 0,14$ & $300 \pm 05$ & $8,14 \pm 0,18$ & $1,01 \pm 0,06$ & $6,21 \pm 0,60$ & $0,57 \pm 0,06$ \\
\hline 12 & 10 & 15 & 23,9 & $3,20 \pm 0,09$ & $330 \pm 05$ & $2,22 \pm 0,05$ & $1,64 \pm 0,06$ & $6,48 \pm 0,83$ & $0,11 \pm 0,02$ \\
\hline 13 & 10 & 7,5 & 0 & $3,04 \pm 0,01$ & $470 \pm 07$ & $4,78 \pm 0,63$ & $1,47 \pm 0,05$ & $9,58 \pm 0,99$ & $1,02 \pm 0,12$ \\
\hline 14 & 10 & 7,5 & 30 & $3,53 \pm 0,07$ & $360 \pm 08$ & $4,00 \pm 0,07$ & $1,41 \pm 0,05$ & $5,94 \pm 0,37$ & $0,98 \pm 0,16$ \\
\hline 15 & 10 & 7,5 & 23,9 & $3,42 \pm 0,08$ & $390 \pm 09$ & $2,59 \pm 0,06$ & $1,69 \pm 0,07$ & $6,20 \pm 0,72$ & $0,53 \pm 0,17$ \\
\hline 16 & 10 & 7,5 & 23,9 & $3,26 \pm 0,14$ & $360 \pm 10$ & $2,73 \pm 0,12$ & $1,64 \pm 0,08$ & $6,31 \pm 0,33$ & $0,57 \pm 0,04$ \\
\hline 17 & 10 & 7,5 & 23,9 & $3,23 \pm 0,04$ & $350 \pm 05$ & $2,70 \pm 0,12$ & $1,71 \pm 0,10$ & $6,16 \pm 0,65$ & $0,55 \pm 0,06$ \\
\hline 18 & 10 & 7,5 & 23,9 & $3,33 \pm 0,06$ & $350 \pm 08$ & $2,88 \pm 0,10$ & $1,79 \pm 0,02$ & $6,26 \pm 0,55$ & $0,57 \pm 0,02$ \\
\hline $\mathrm{C}$ & - & - & - & $2,58 \pm 0,01$ & $610 \pm 17$ & $9,84 \pm 0,54$ & $1,72 \pm 0,01$ & $4,99 \pm 0,32$ & $1,11 \pm 0,12$ \\
\hline
\end{tabular}

*Média de três repetições \pm desvio padrão; ** média de seis repetições \pm desvio padrão, $\mathrm{C}$ - Controle; $\mathrm{X}_{1}, \mathrm{X}_{2}$ e $\mathrm{X}_{3}-$ níveis reais de isolado proteico de soja, albumina de ovo modificada e desidratada e farinha de arroz pré-gelatinizada, respectivamente, expressos em porcentagem.

2005), sendo esse o motivo pelo qual não contribuem para o IAA.

$\operatorname{IAA}(\%)=3,26+0,28 x_{1}+0,13 x_{3}$ (Equação 1)

Umidade e características de cozimento das massas alimentícias

A umidade das massas alimentícias variou entre 9,99 e $13,98 \%$ e os dados das características de cozimento estão apresentados na tabela 2 . O processo de secagem realizado garantiu que todos os ensaios e a amostra padrão apresentassem teor de umidade abaixo de $14 \%$. O TC dos ensaios do delineamento variou entre 300 e $525 \mathrm{~s}$ ( 5 e $8,75 \mathrm{~min}$ ), sendo influenciado estatisticamente $(\mathrm{P}<0,10)$ pelo IPS, ALB e FAG. A ANOVA mostrou valor de $\mathrm{R}^{2}$ de 0,7827 , razão entre $F_{\text {calc }}$ e $F_{\text {tab }}$ de 4,82 e p-valor $<0,001$. O modelo matemático está apresentado na equação 2 . Conforme pode ser observado na figura 1 , menores valores de TC foram obtidos nas maiores concentrações de IPS e intermediários de FAG, enquanto que a adição de ALB apresentou baixa influência neste parâmetro. Todos os ensaios apresentaram valores menores de
TC em relação à amostra padrão $(610 \mathrm{~s}=10,17 \mathrm{~min})$. Provavelmente, a diluição do amido da FA, a alta capacidade de hidratação do IPS e o uso de FAG foram responsáveis pela diminuição do TC. Todos os valores de TC para os ensaios foram inferiores aos encontrados por CHILLO et al. (2008) em macarrão tipo spaghetti de semolina de trigo durum, que foi de 552s (9,20min), exceto para a amostra padrão deste experimento.

$\mathrm{TC}(\mathrm{s})=351,76-59,42 \mathrm{x}_{1}+29,88 \mathrm{x}_{1}{ }^{2}+28,99 \mathrm{x}_{3}{ }^{2}+31,25 \mathrm{x}_{2} \mathrm{x}_{3}$ (Equação 2)

Variando entre 2,22 e $9,84 \%$, a PS foi influenciada $(\mathrm{P}<0,10)$ pela adição de IPS, ALB e FAG. O valor de $\mathrm{R}^{2}$ foi de $0,9628, \mathrm{~F}_{\text {calc }} / \mathrm{F}_{\text {tab }}$ de 19,83 e p-valor $<0,001$, segundo a ANOVA. O modelo matemático está exposto na equação 3. PS mínima ocorreu com o uso de IPS, ALB e FAG em torno de $15 \%$ (Figura 1).

$\mathrm{PS}(\%)=2,72-1,08 \mathrm{x}_{1}+0,63 \mathrm{x}_{1}^{2}-1,98 \mathrm{x}_{2}+0,87 \mathrm{x}_{2}^{2}+0,59 \mathrm{x}_{3}^{2}+0,88 \mathrm{x}_{1} \mathrm{x}_{2}$ (Equação 3)

Ciência Rural, v.43, n.5, mai, 2013. 


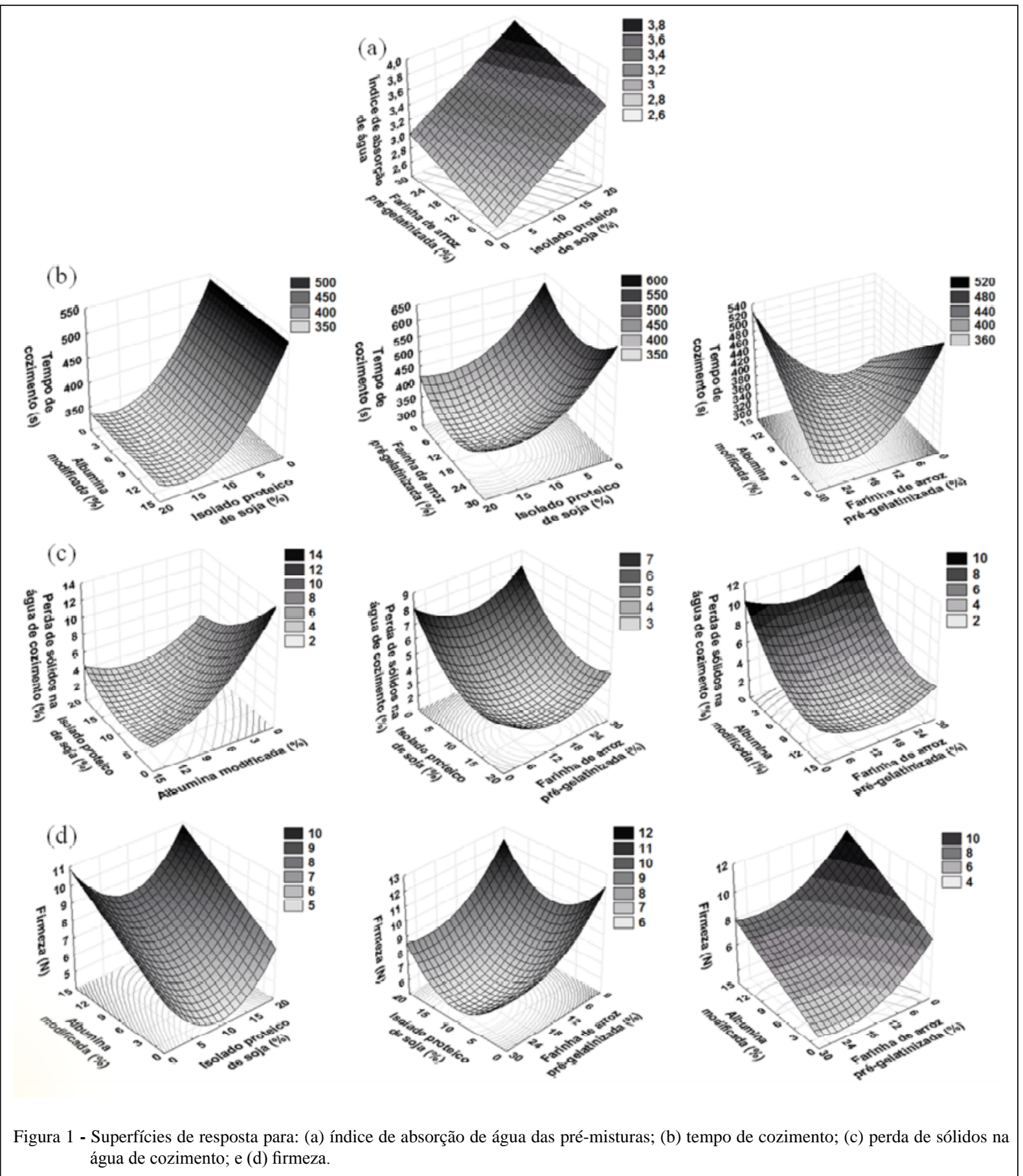

Em produtos sem glúten, a PS é resultado da lixiviação de amido gelatinizado livre, por isso é dependente do grau de gelatinização do amido (MARTI et al., 2010). Provavelmente, o IPS e a ALB formaram uma rede proteica sobre os grânulos de amido, dificultando o lixiviamento deste durante o processo de cozimento, contribuindo com a redução da PS. A amostra padrão apresentou maior PS
$(9,84 \%)$ em relação aos ensaios, no entanto, abaixo do valor encontrado por MARTI et al. (2010), que foi de $15,9 \%$ para massa de arroz parboilizado obtida por processo convencional, enquanto que CHILLO et al. (2008) encontraram valor de 7,81\% para espagueti de semolina de trigo durum.

O AP dos ensaios variou entre 1,01 e 1,79, não sendo influenciado pelas variáveis independentes 
dentro da faixa estudada. Os ensaios apresentaram valores menores de AP em relação à amostra padrão.

Propriedades de textura

Os valores de firmeza e adesividade obtidos estão apresentados na tabela 2 . A firmeza apresentou valores entre 4,82 e $11,13 \mathrm{~N}$, sendo influenciada $(\mathrm{P}<0,10)$ pela adição de IPS, ALB e FAG. A ANOVA mostrou valor de $\mathrm{R}^{2}$ de $0,7553, \mathrm{~F}_{\text {calc }} / \mathrm{F}_{\text {tab }}$ de 4,13 e p-valor $<0,001$ e o modelo matemático está na equação 4. A firmeza da massa foi maior com maiores teores de IPS e ALB e menores teores de FAG, conforme pode ser observado na figura 1 . Os dados mostraram que todos os ensaios apresentaram maiores valores de firmeza em relação à amostra padrão.

Firmeza $(\mathrm{N})=6,26+0,94 \mathrm{x}_{1}{ }^{2}+1,15 \mathrm{x}_{2}-1,09 \mathrm{x}_{2}{ }^{2}+0,51 \mathrm{x}_{3}{ }^{2}$

(Equação 4)

SIVARAMAKRISHNAN et al. (2004) citam que a pré-gelatinização do amido para a produção de massas favorece a integridade do produto, devido a uma reorganização da estrutura molecular da amilopectina, em virtude da retrogradação, resultando em massas alimentícias com maior firmeza. Além disso, a provável formação de rede proteica sobre os grânulos de amido também pode ter resultado em um produto com maior firmeza. BHATTACHARYA et al. (1999) encontraram valores médios de 7,50N para a firmeza de massas de arroz (rice noodles) de 11 variedades diferentes deste cereal, resultado semelhante aos ensaios deste experimento, porém maior que da amostra padrão. VERNAZA et al. (2012) obtiveram valores de firmeza de 29,61 e $46,93 \mathrm{~N}$ para massa tipo espaguete com farinha de trigo e semolina de trigo durum, respectivamente, ambos com adição de $0,35 \%$ de monoglicerídio destilado.

Variando entre 0,11 e $1,03 \mathrm{~N}$, a adesividade não foi influenciada por nenhuma das variáveis independentes em estudo. Verificou-se uma tendência de redução da adesividade das massas alimentícias adicionadas de IPS, ALB e FAG, em relação à amostra controle. ORMENESE \& CHANG (2004) encontraram valores de $0,75 \mathrm{~N}$ para fettucini de arroz.

Validação dos modelos matemáticos

Considerando que as propriedades de cozimento e textura são de grande importância para as características das massas, e que se objetiva menor tempo de cozimento, menor perda de sólidos e maior firmeza (com características de massa al dente), o ponto ótimo foi definido como aquele com a adição de $17 \%$ de IPS, $15 \%$ de ALB e $15 \%$ de FAG (valores codificados de 1,18, 1,68 e 0, respectivamente). Para IAA, TC, PS e firmeza, foram obtidos valores experimentais para o ponto ótimo de $3,42 \pm 0,10$, $350 \pm 15 \mathrm{~s}, 2,90 \pm 0,02 \%$ e $5,79 \pm 0,18 \mathrm{~N}$, respectivamente. Considerando que os valores preditos pelos modelos matemáticos foram de 3,59,323s, 3,20\% e $6,42 \mathrm{~N}$, respectivamente, os desvios relativos encontrados foram de $-4,83,8,28,-9,27$ e $-9,94$, respectivamente. Devido aos baixos desvios relativos $(<10 \%)$ apresentados na validação, os modelos matemáticos encontrados predizem os valores experimentais. Teoricamente, considerando os valores de proteína obtidos na análise das matérias-primas, o ponto ótimo apresentaria um teor proteico de 24,13\% (massa seca com $10 \%$ de umidade). Considerando que essa massa alimentícia tenha um aumento de peso no cozimento de 1,5 (valores médios obtidos no delineamento experimental), o produto pronto para o consumo apresentaria $16,08 \%$ de proteína.

\section{CONCLUSÃo}

Os resultados mostraram que o uso de IPS, ALB e FAG são importantes para a obtenção de massas com características tecnológicas melhores que a amostra controle. Obteve-se um produto final com menor TC, baixa PS e maior firmeza do que a amostra controle, características importantes neste tipo de produto. Sugere-se que a análise sensorial pode determinar a aceitação do produto. A adição de $17 \%$ de IPS, $15 \%$ de ALB e $15 \%$ de FAG na FA apresentaram as melhores condições tecnológicas, e os modelos matemáticos foram validados e podem predizer as respostas analisadas pelo delineamento utilizado.

\section{AGRADECIMENTOS}

Os autores agradecem ao Conselho Nacional de Desenvolvimento Científico e Tecnológico (CNPq), à Coordenação de Aperfeiçoamento de Pessoal de Nível Superior (Capes), à JOSAPAR, à SOLAE e à AB Brasil.

\section{REFERÊNCIAS}

AACC (AMERICAN ASSOCIATION OF CEREAL CHEMISTS). Approved methods. 11.ed. St. Paul, 2010.

ANDERSON, R.A. et al. Gelatinization of corn grits by roll and extrusion cooking. Cereal science today. v.14, p.4-7, 1969.

BHATTACHARYA, M. et al. Physicochemical properties related to quality of rice noodles. Cereal Chemistry, v.76, p.861-867, 1999. Disponível em: <http://dx.doi.org/10.1094/ CCHEM.1999.76.6.861>. Acesso em: 30 jul. 2012. doi: 10.1094/ CCHEM.1999.76.6.861.

BRASIL. Resolução RDC ANVISA/MS nº 268, de 22 de setembro de 2005. Regulamento técnico para produtos proteicos de origem

Ciência Rural, v.43, n.5, mai, 2013. 
animal. Diário Oficial da União, Brasília, DF, 23 set. 2005. Disponível em: <http://e-legis.anvisa.gov.br/>. Acesso em: 13 jul. 2012.

CATASSI, C.; FASANO, A. Celiac disease diagnosis: simple rules are better than complicated algorithms. American Journal of Medicine, v.123, p.691-693, 2010. Disponível em: <http://www. ncbi.nlm.nih.gov/pubmed/20670718>. Acesso em: 10 jul. 2012. doi:10.1016/j.amjmed.2010.02.019.

CHILLO, S. et al. Influence of the addition of buckwheat flour and durum wheat bran on spaghetti quality. Journal of Cereal Science, v.47, p.144-152, 2008. Disponível em: <http://dx.doi. org/10.1016/j.jcs.2007.03.004>. Acesso em: 05 jul. 2012. doi: 10.1016/j.jcs.2007.03.004.

CLERICI, M.T.P.S; EL-DASH, A.A. Technological properties of pregelatinized rice flour obtained by thermoplastic extrusion. Ciência e Agrotecnologia, v.32, p.1543-1550, 2008. Disponível em: <http:// dx.doi.org/10.1590/S1413-70542008000500028>. Acesso em: 13 jul. 2012. doi: 10.1590/S1413-70542008000500028.

EGBERT, W.R. Isolated soy protein: technology, properties, and applications. In: LIU, K. Soybeans as functional foods and ingredients. Illinois: AOCS, 2004. Cap. 7, p.134-162.

FDA (FOOD AND DRUG ADMINISTRATION). Food labeling: helth clains; soy protein and coronary heart disease. Rome, 1999. V.64. (Federal Register, n.206).

FERNANDES, S.M. et al. Caracterização química de extratos hidrossolúveis desidratados de arroz e soja. Pesquisa Agropecuária Brasileira, v.35, p.843-847, 2000. Disponível em: <http://dx.doi.org/10.1590/S0100-204X2000000400023>. Acesso em: 25 jun. 2012. doi: 10.1590/S0100-204X2000000400023.

HUMMEL, C. Macaroni products: manufacture, processing and packing. London: Food Trade, 1966. 287p.

MARTI, A. et al. Rice-based pasta: A comparison between conventional pasta-making and extrusion-cooking. Journal of
Cereal Science, n.52, p.404-409, 2010. Disponível em: <http:// dx.doi.org/10.1016/j.jcs.2010.07.002>. Acesso em: 10 jul. 2012. doi: $10.1016 /$ j.jcs.2010.07.002

NABESHIMA, E.H.; EL-DASH, A.A. Modificação química da farinha de arroz como alternativa para o aproveitamento dos subprodutos do beneficiamento do arroz. Boletim do Centro de Pesquisa de Processamento de Alimentos, v.22, n.1, p.107-120, 2004.

ORMENESE, R.C.S.C.; CHANG, Y.K. Rice pasta formulation for a conventional pasta manufacturing process: a response surface methodology study. Food Science and Biotechnology, v.13, n.2, p.130-135, 2004.

PLANCKEN, I.V.D et al. Combined effect of high pressure and temperature on selected properties of egg white proteins. Innovative Food Science and Emerging Technologies, v.6, p.11-20, 2005. Disponível em: <http://dx.doi.org/10.1016/j. ifset.2004.10.002>. Acesso em: 25 jun. 2012. doi: 10.1016/j. ifset.2004.10.002.

SIVARAMAKRISHNAN, H.P. et al. Rheological properties of rice dough for making rice bread. Journal of Food Engineering, v.62, p.37-45, 2004. Disponível em: <http://dx.doi.org/10.1016/ S0260-8774(03)00169-9>. Acesso em: 04 jul. 2012. doi: 10.1016/ S0260-8774(03)00169-9.

TACO. Tabela brasileira de composição de alimentos. 4.ed. ver e ampl. Campinas: NEPA - UNICAMP, 2011. 161p. Disponível em: <http://www.unicamp.br/nepa/taco/>. Acesso em: 12 jul. 2012.

VERNAZA, M.G. et al. Effect of supplementation of wheat flour with resistant starch and monoglycerides in pasta dried at high temperatures. International Journal of Food Science and Technology, v.47, p.1302-1312, 2012. Disponível em: <http:// onlinelibrary.wiley.com/doi/10.1111/j.1365-2621.2012.02974.x/ pdf>. Acesso em: 13 jul. 2012. doi: 10.1111/j.13652621.2012.02974.x. 